\title{
Alterations of Genetic Variants and Transcriptomic Features of Response to Tamoxifen in the Breast Cancer Cell Line
}

\section{Mahnaz Nezamivand-Chegini}

Shiraz University

Hamed Kharrati-Koopaee

Shiraz University https://orcid.org/0000-0003-2345-6919

seyed taghi Heydari ( $\square$ heydari.st@gmail.com )

Shiraz University of Medical Sciences https://orcid.org/0000-0001-7711-1137

\section{Hasan Giahi}

Shiraz University

Ali Dehshahri

Shiraz University of Medical Sciences

Mehdi Dianatpour

Shiraz University of Medical Sciences

Kamran Bagheri Lankarani

Shiraz University of Medical Sciences

\section{Research}

Keywords: Tamoxifen, breast cancer, genetic variants, RNA-seq.

Posted Date: August 17th, 2021

DOl: https://doi.org/10.21203/rs.3.rs-783422/v1

License: (9) (i) This work is licensed under a Creative Commons Attribution 4.0 International License. Read Full License 


\section{Abstract \\ Background}

Breast cancer is one of the most important causes of mortality in the world, and Tamoxifen therapy is known as a medication strategy for estrogen receptor-positive breast cancer. In current study, two hypotheses of Tamoxifen consumption in breast cancer cell line (MCF7) were investigated. First, the effect of Tamoxifen on genes expression profile at transcriptome level was evaluated between the control and treated samples. Second, due to the fact that Tamoxifen is known as a mutagenic factor, there may be an association between the alterations of genetic variants and Tamoxifen treatment, which can impact on the drug response.

\section{Methods}

In current study, the whole-transcriptome (RNA-seq) dataset of four investigations (19 samples) were derived from European Bioinformatics Institute (EBI). At transcriptome level, the effect of Tamoxifen was investigated on gene expression profile between control and treatment samples. Moreover, Tamoxifen is known as a mutagenic factor, therefore, its contribution to alterations of genetic variants and drug response were examined.

\section{Results}

Results achieved from RNA-seq analysis indicated the contribution of several candidate genes to tumor suppression process and consequently, the achievement of an effective treatment. For instance, XIAPassociated factor 1 (XAF1) was reported as an up-regulated gene under Tamoxifen therapy. XAF1 is a tumor suppressor that contributes to the apoptosis induction and tumor growth inhibition along with TP53. Results of gene ontology enrichment analysis of differential gene expressions indicated that most of them could considerably lead to the cell death, apoptosis, and negative regulation of proteolysis process. Findings achieved from evaluating Tamoxifen mutagenicity effect on drug response was not confirmed perfectly. The most reported candidate genes, which were related to differential genetic variants between control and treated samples, played the oncogene and tumor suppressor dual roles and also their exact roles in breast cancer were not investigated precisely.

\section{Conclusion}

At transcriptome level, Tamoxifen consumption in MCF7 cell line could be associated with candidate genes and biological pathways that contribute to the apoptosis, proteolysis, and tumor suppression. The mutagenicity effect of Tamoxifen and its contribution to drug response was not confirmed perfectly. 


\section{Background}

Cancer is one of the most important causes of mortality in the world and breast cancer is a common disease among women. Hormonal therapy is a medical strategy for breast cancer treatment (Akram et al. 2017). Tamoxifen is considered as the main non-steroidal drug in breast cancer treatment for postmenopausal women (Abo-Touk et al. 2010), which inhibits the estrogen activity through binding to the estrogen receptor competitively (Geisler, 2011).

There are several investigations carried out with the purpose of illustrating the hormonal therapy effects that provide a better understanding of the drug response mechanism and select an effective strategy for the therapeutic period (AlFakeeh and Brezden-Masley, 2018; Szostakowska et al. 2019; Fan et al. 2015; Moiseenko et al. 2017). The appropriate drug response is a complex interdependent procedure that is highly dependent upon several factors including the genetic variants background, lifestyle, climate, smoking, and alcohol consumption (Levy and Polatsek, 2002; Bachtiar and Lee. 2013).

Genetic variants refer to the genetic differences between individuals of a population (Kharrati et al., 2012). DNA is a vulnerable molecule against various mutagens including ultraviolet, toxins, chemical agent, and free radicals (Koopaee and Esmailizadeh, 2014). Recently, high-throughput sequencing platforms have been applied as powerful tools in order to investigate the association between a massive number of genetic variants and drug response (Madian et al. 2012; Esfandiari et al., 2020).

It is shown that Tamoxifen has a mutagenic effect on the endometrium cells and increases the incidence of endometrial tumors (White and Smith, 1996). Results of evaluating the rat hepatic tissue showed that activated Tamoxifen could bind to guanine N2-position of DNA and consequently, produce pro-mutagenic lesion (Brown, 2009). More importantly, it was found that Tamoxifen mutagenicity effect induced DNA damages in human endometrial cells (Liapis et al., 2008). Considering the in vitro conditions, Tamoxifen would lead to the gene mutations and increased incidence of abnormal chromosomal structures in rat liver tissues (Davies et al., 1997). All of the above-mentioned literature reviews indicated that Tamoxifen could play a critical role in the alterations of genetic variants background. There are several examples about the role of genetic variants in drug response. To achieve a therapeutic effect, there has to be an interaction between the drug and its target. DNA variations can both increase and decrease the binding affinity of a drug to its target. In addition, genetic variations can transform the antagonist role of drug into an agonist one; therefore, the most common problem of treatment procedures is resistant mutations in drug targets. Tamoxifen blackens Estrogen (ER-positive cancer) in the breast cancer treatment procedure and consequently, decreases the risk of cancer recurrence. Tamoxifen is an anti-estrogen hormone that inhibits the Estrogen receptors; however, its efficiency would be decreased as a result of the occurrence of mutations in estrogen receptors and it leads to the conversion of RE-positive into progesterone-positive cancer. Consequently, it causes the drug resistance development and nonresponse to treatment (Wardell et al. 2019).

It is noteworthy that genetic variations may contribute to drug metabolism and influence the drug response. For instance, if the drug is rapidly metabolized, its concentration will decrease due to the 
weaker drug action or side effects. Considering slower metabolism procedures, higher drug levels would result in the stronger or longer actions and side effects (Levy and Polatsek, 2002).

Gene expression analysis at transcriptome level is considered as another considerable tool that can show the effects of hormone therapy on genes expression profiles. It has been shown through several studies that there is a close association between transcriptome response and therapeutic drug consumption (Sjöström et al., 2020; Fekete et al., 2019; Men et al., 2018; Kumari et al., 2017 and Selli et al., 2016). It was found from one of the main investigations that carried out a comprehensive transcriptomic analysis on Tamoxifen resistance that ncRNAs profiling breast cancer cells would provide a new light on the identification of novel endocrine resistance biomarkers (Gao et al., 2020). Lanceta et al. (2020) carried out RNA sequencing (RNA-seq) and pathway analysis in ER + MCF7, and reported 2183 up-regulated and 1548 down-regulated transcripts that contributed to cell cycle, DNA replication, and DNA repair and autophagy.

Current study investigates two hypotheses of Tamoxifen consumption in breast cancer cell line (MCF7). First, there may be an association between genetic variants alterations and Tamoxifen treatment due to the fact that Tamoxifen is a mutagenic factor that impacts on the drug response. Second, how does Tamoxifen affect the gene expression profile at transcriptome level? Investigating Tamoxifen therapychanged genetic variants and genes expression could be useful to understand the drug response mechanism; also, it would provide a new insight to the increase of the chance of survival, decrease the side effects, and select an appropriate strategy for the therapy period.

\section{Materials}

The summary of data collections, genetic variant, and RNA-seq analyses are represented in Figure 1.

\subsection{Data collection}

In current study, the whole-transcriptome (RNA-seq) dataset of four investigations were derived from EBI (https://www.ebi.ac.uk/). More details of collected datasets were provided in Table1.

Table1. More details of RNA-seq datasets to discover the genetic variants and gene expression analysis

\begin{tabular}{lllll} 
Accession number & Control samples & Treatment samples & Drug type & Cell line \\
\hline E-MTAB-822 & 1 & 2 & Tamoxifen & MCF7 \\
\hline E-GEOD-59536 & 1 & 1 & Tamoxifen & MCF7 \\
\hline E-GEOD-62613 & 1 & 1 & Tamoxifen & MCF7 \\
\hline E-GEOD-78199 & 6 & 6 & Tamoxifen & MCF7 \\
\hline Total & 9 & 10 & - & -
\end{tabular}

\subsection{Quality control and trimming}


It was observed that various parameters led to the appropriate quality control functions in CLC Genomic Workbench (12) for each sample including length distribution, GC content, ambiguous base content, Phred score, nucleotide contribution, enrich 5 mers, and duplicate sequences (Kharrati-Koopaee et al., 2019). Due to the fact that the adaptor sequences were cleaned in the achieved datasets, the adaptor trimming was not achieved.

\subsection{Genetic variants analysis}

\subsubsection{Reference genome and alignments analysis}

The reference genome (hg38) and all annotations were downloaded from Ensembl database (www.ensembl.org). Mapping short reads was carried out against reference genome through CLC Genomics Workbench 12 based on the following parameters: masking track= mRNA sequence, mismatch cost $=2$, cost of insertions and deletions $=$ linear gap cost, insertion cost $=3$, deletion cost $=3$, length fraction $=0.7$, and similarity fraction $=0.8$ (Mortazavi et al., 2008).

\subsubsection{Variant calling and statistical analysis}

CLC genomics workbench 12 applied the variant detections algorithm; also, there no constant ploidy level was observed within cancer cell lines. Therefore, the variant calling procedure was carried out using the low frequency algorithmon the basis of the following parameters: required variant probability $(\%)=95.0$ ignore broken pairs $=$ yes, minimum coverage $=10$, minimum count $=2$, minimum frequency $(\%)=30$, base quality filter $=$ Yes, neighborhood radius $=15$, minimum central quality $=30$, and minimum neighborhood quality $=25$ (Doan et al., 2012). Chi-square test was performed with the purpose of explaining the differences of genetic variants distribution between control and treated samples.

\subsubsection{Comparing the variants and gene ontology (GO) enrichment analysis}

After performing the variants calling process, genetic variants of treatment samples were compared with the reads of control samples in order to remove the common genetic variants among treated and control samples. The file of gene ontology association, which included the gene names and associated gene ontology terms, was downloaded from the gene ontology consortium (http://geneontology.org/) and imported to CLC Genomic Workbench 12. Moreover, differential genetic variants were applied to perform GO enrichment analysis at levels of biological process, molecular function, and cellular component. The significance of the level of GO analysis was determined to be 0.01 .

\subsection{RNA-seq analysis}

RNA-seq analysis was carried out based on the annotated genome reference with transcripts using various parameters including mismatch cost $=2$, insertion cost $=2$, deletion cost $=2$, length fraction $=0.8$, and similarity fraction= 0.8 ; also, the expression value was calculated through RPKM implementation. Reads per kilobase of transcript, per million mapped reads (RPKM) is a normalized unit of transcript expression. Results achieved from RNA-seq analysis of treated and control samples were compared in order to 
identify the differential genes expression (DGE). The significant level $(P \leq 0.01)$ was considered as a threshold of DGEs detection. Heat map and volcano plot were implemented to visualize the RNA-seq analysis results; also, the process of RNA-seq analysis was carried out using CLC genomic workbench 12.

\section{Results}

\subsection{Genetic variants detection}

Results of quality control indicated that there was not any necessary special trimming strategy for RNAseq datasets. To minimize the alignment errors, $5 \%$ of the short reads with the lowest Phred scores were removed. Results of alignments of short reads against reference genome (hg 38) are provided in Table2. Furthermore, $66 \%-89 \%$ was reported for the mapping percentage.

Table2. The mapping summary of short reads against reference genome 


\begin{tabular}{|c|c|c|c|}
\hline Accession number & Samples & Total reads & Mapped reads $\%$ \\
\hline E-GEOD-59536 & $\mathrm{T} 1$ & 89713168 & 68.80 \\
\hline E-GEOD-62613 & $\mathrm{T} 2$ & 112247072 & 85.91 \\
\hline \multirow[t]{6}{*}{ E-GEOD-78199 } & T3 & 34981408 & 81.22 \\
\hline & T4 & 36012214 & 81.20 \\
\hline & T5 & 40160428 & 82.10 \\
\hline & T6 & 41384146 & 82.05 \\
\hline & T7 & 39870210 & 81.72 \\
\hline & T8 & 41063128 & 81.74 \\
\hline \multirow[t]{2}{*}{ E-MTAB-822 } & T9 & 10069398 & 87.85 \\
\hline & T10 & 12018685 & 83.10 \\
\hline E-GEOD-59536 & C1 & 97511228 & 66.10 \\
\hline E-GEOD-62613 & $\mathrm{C} 2$ & 103822108 & 87.37 \\
\hline \multirow[t]{6}{*}{ E-GEOD-78199 } & C3 & 39172180 & 82.47 \\
\hline & C4 & 40347538 & 82.44 \\
\hline & C5 & 44328838 & 80.16 \\
\hline & C6 & 45695050 & 80.15 \\
\hline & C7 & 36382948 & 82.53 \\
\hline & C8 & 37484422 & 82.50 \\
\hline E-MTAB-822 & C9 & 8569125 & 89.25 \\
\hline
\end{tabular}

T: treated samples, C: control samples

There were almost 5.8 million genetic variants identified in current study including single nucleotide variations (SNVs), multi nucleotide variations (MNVs), insertion, deletion, and replacement. The highest and lowest frequencies among detected genetic variants were respectively related to SNVs and replacement. More details of genetic variants frequencies are provided in Figure 2.

To investigate the effect of Tamoxifen on genetic variants distribution within control and treated samples, a statistical analysis was separately carried out for each genetic variant on the basis of chi-square test for total genetic variants in the control and treatment samples. Results showed that genetic variants distribution within control and treated samples was significant $(P \leq 0.05)$. Also, it was found that all of the genetic variants distributions in control and treatment samples were significant (Table 3), which indicated the possible effects of Tamoxifen on the genetic variants frequency. 
Table3. Results of statistical analysis of genetic variants distribution in control and treatment samples

\begin{tabular}{|ll|}
\hline Genomic variants & P-value \\
\hline SNV $^{* *}$ & 0.00006 \\
\hline MNV**$^{* * *}$ & 0.0001 \\
\hline Insertion $^{* *}$ & 0.0003 \\
\hline Deletion $^{* *}$ & 0.0012 \\
\hline Replacement $^{* *}$ & 0.001 \\
\hline
\end{tabular}

Results of the comparison between genetic variants of control and treatment samples indicated that there were 117 differential genetic variants. Among all of the differential variants, 13 genetic variants were located in the coding regions and 12 variants led to the amino acid sequence transformation within the protein structure. Table 4 shows more details of differential genetic variants.

Table 4. The classification of differential genetic variants within control and treatment samples

\begin{tabular}{|lllll|}
\hline $\begin{array}{l}\text { Genetic } \\
\text { variants }\end{array}$ & $\begin{array}{l}\text { Differential } \\
\text { variants }\end{array}$ & $\begin{array}{l}\text { Coding } \\
\text { region }\end{array}$ & $\begin{array}{l}\text { Non-coding } \\
\text { regions }\end{array}$ & $\begin{array}{l}\text { Amino acid } \\
\text { changes }\end{array}$ \\
SNV & 93 & 12 & 81 & 11 \\
MNV & 9 & 1 & 8 & 1 \\
Insertion & 2 & 0 & 2 & 0 \\
Deletion & 13 & 0 & 13 & 0 \\
Replacement & 0 & 0 & 0 & 0 \\
\hline Total & 117 & $\mathbf{1 3}$ & 104 & 12 \\
\hline
\end{tabular}

The process of gene ontology enrichment analysis of differential genetic variants was carried out at three levels of biological process, cellular component, and molecular function; therefore, a total number of 77 significant $\mathrm{GO}$ terms were reported (Table 5). At the biological process level, the most repetitive of reported overlapping gene names were GEN1, HSPA5, NSMCE2, AURKA, and DDX11 candidate genes. GEN1 (Flap endonuclease GEN homolog 1) encoded a member of Rad2/xeroderma pigmentosum group $G$ nuclease family. As it was observed for BRCA1 and BRCA2, findings showed that GEN1 contributed to resolve the Holliday junction in the homologous recombination. It is noteworthy that Holliday junction can play a vital role in the cancer chemo-sensitivity (Wu et al., 2016). Somatic truncating GEN1 mutations have been reported in breast cancers; therefore, it would indicate the fact that GEN1 may be a predisposition gene in breast cancer. However, it was shown that although it plays a critical role in the double-strand DNA break repair, GEN1 would not make any appreciable contribution to breast cancer susceptibility through acting as a high- or intermediate-penetrance breast cancer predisposition gene 
such as BRCA1, BRCA2, CHEK2, ATM, BRIP1, and PALB2 (Turnbull et al., 2010). Sun et al. (2014) suggested that GEN1 would play a vital role in DNA damage response; therefore, its alteration could lead to the breast cancer. HSPA5 (Heat-shock protein 5) is considered as a marker of poor prognosis in breast cancer patients, and plays a critical role in promoting the drug resistance and metastasis (Chang et al., 2014). A close association was observed between the cancer behaviors of heat shock proteins family; however, all members of HSP family have not been studied completely (Zoppino et al., 2018). NSMCE2 is an E3 SUMO ligase and a subunit of SMC5/6 complex that could be associated with DNA repair (Pond et al., 2019). Although SMC5/6 complex functions were not described precisely, it was reported that it could act as a tumor suppressor in mice (Jacome et al., 2015). AURKA (Aurora Kinase A) is a serine/threonine kinase that contributes to the regulation of cell cycle progression; therefore, it could be a potential cancer susceptibility gene (Cox et al., 2006). Furthermore, it is considered as a promising target in the treatment processes of patients with cancer (Staff et al., 2010). DDX11 is a DNA helicase that plays a role in DNA replication, sister chromatid cohesion establishment, and general chromosome structure. The effects of DNA helicases among patients with cancer are dependent upon their genetic background and tumor type; however, it has not been illustrated precisely and there are various reports of their activities. For example, it was suggested that DNA helicase may have a tumor suppressor function, and the expression level of several DNA helicases at pre-cancerous stages would be increased significantly (Mahtab.et al., 2021)

Results achieved from molecular function analysis indicated that the most frequent enriched candidate genes in significant GO term were IL6ST, COX15, and FNTA.

Interleukin-6 (IL-6) is a cytokine released by various cells such as cancerous cells, and plays a vital role in the expansion and differentiation of tumor cells (Masjedi et al., 2018). It was also shown that IL6ST may respectively act as a main factor and a tumor suppressor gene in triple-negative breast (TBC) progression, and diagnosis and treatment procedures (Jia et al., 2021). Additionally, IL6ST was reported as a specific candidate gene for TBC. Therefore, the expression of IL6ST and other three genes (ANKRD30A, ANP32E, and DSC2) classified TBC from non-TBC (Mathe.et l., 2015). COX15 encodes cytochrome C Oxidase subunit 15 and contributes to mitochondrial respiratory chain (UniProtKB: Q7KZN9). Gao.et al. (2017) reported that the high-level expression of $C O X 5 B$ candidate gene was associated with a poor prognosis in breast cancer. It was suggested that the level of $C O X 5 B$ protein may be related to the tumor size; also, its up-regulated form showed a worse disease free-survival. However, there was not enough evidence to explain the clinical implications of COX5B in breast cancer. FNTA is located on chromosome 8 and encodes the subunit alpha of protein farnesyltransferase (FTase) enzyme (UniProtKB: P49354). It was found that FNTA could be a key gene for tumor progression; moreover, its abnormal copy numbers were associated with pathological transformations of breast cancer. Therefore, it could be considered as a main target of developing drugs (Tian et al., 2020). The cellular component analysis showed that nucleus and nucleoplasm were the most important cellular parts that may contribute to the hormone therapy.

Table5. Results of gene ontology enrichment analysis of differential genetic variants between control and treated samples 
GO type GO term Description

Overlapping gene name

Biological 0000722 Telomere maintenance via recombination process

NSMCE2,

SMC6

0007052 Mitotic spindle organization

AURKA, RAN,

TTK

0007051 Spindle organization

AURKA, TTK

0007041 Lysosomal transport

IGF2R, VPS54

0090398 Cellular senescence

NSMCE2,

SMC6

0000724 Double-strand break repair via homologous

GEN1, recombination

NSMCE2, YY1

0034612 Response to tumor necrosis factor

ADAM10,

GGT1

0001315 Age-dependent response to reactive oxygen species

SOD2

0003069 Vasodilation by acetylcholine involved in regulation of systemic arterial blood pressure

0033316 Meiotic spindle assembly checkpoint

TTK

0036316 SREBP-SCAP complex retention in endoplasmic reticulum INSIG1

0051089 Constitutive protein ectodomain proteolysis

ADAM10

0060904 Regulation of protein folding in endoplasmic reticulum

HSPA5

0061015 snRNA import into nucleus

RAN

0070862 Negative regulation of protein exit from endoplasmic reticulum

INSIG1

0071139 Resolution of recombination intermediates

GEN1

0090044 Positive regulation of tubulin deacetylation

FNTA

1901303 Negative regulation of cargo loading into COPII-coated vesicle

INSIG1

1901668 Regulation of superoxide dismutase activity

$S Z T 2$

1903891 Regulation of ATF6-mediated unfolded protein response

HSPA5

1903897

Regulation of PERK-mediated unfolded protein response

HSPA5

1904426 positive regulation of GTP binding

CLN5

0060271 cilium assembly

IFT80, INTU,

SEPT7, WDR19 


\begin{tabular}{lll}
0031297 & Replication fork processing & DDX11, GEN1 \\
\hline 0018279 & Protein N-linked glycosylation via asparagine & $\begin{array}{l}\text { MAGT1, } \\
\text { MCFD2 }\end{array}$ \\
\hline 0000303 & Response to superoxide & SOD2 \\
\hline 0000768 & Syncytium formation by plasma membrane fusion & ERVW-1 \\
\hline 0006784 & Heme a biosynthetic process & COX15 \\
\hline 0006949 & Syncytium formation & ERVW-1 \\
\hline 0031179 & Peptide modification & GGT1 \\
\hline 0034085 & Establishment of sister chromatid cohesion & DDX11 \\
\hline 0035281 & Pre-miRNA export from nucleus & RAN \\
\hline 0035437 & $\begin{array}{l}\text { Maintenance of protein localization in endoplasmic } \\
\text { reticulum }\end{array}$ & HSPA5 \\
\hline 0070085 & Glycosylation & CLN5 \\
\hline 0071140 & Resolution of mitotic recombination intermediates & GEN1 \\
\hline 0072369 & $\begin{array}{l}\text { Regulation of lipid transport by positive regulation of } \\
\text { transcription from RNA polymerase Il promoter }\end{array}$ & HNRNPK \\
\hline 0090045 & Positive regulation of deacetylase activity & FNTA \\
\hline 0097421 & Liver regeneration & AURKA \\
\hline
\end{tabular}

Table5. Continued 
GO type GO term Description

Overlapping gene name

Biological process
0035437
Maintenance of protein localization in endoplasmic reticulum

HSPA5

\begin{tabular}{ll}
0070085 & Glycosylation \\
\hline 0071140 & Resolution of mitotic recombination intermediates \\
\hline 0072369 & $\begin{array}{l}\text { Regulation of lipid transport by positive regulation of } \\
\text { transcription from RNA polymerase Il promoter }\end{array}$ \\
\hline 0090045 & Positive regulation of deacetylase activity \\
\hline 0097421 & Liver regeneration \\
\hline 1901980 & $\begin{array}{l}\text { Positive regulation of inward rectifier potassium channel } \\
\text { activity }\end{array}$ \\
\hline 1990700 & Nucleolar chromatin organization \\
\hline 2001076 & $\begin{array}{l}\text { Positive regulation of metanephric ureteric bud } \\
\text { development }\end{array}$ \\
\hline
\end{tabular}

0006631 Fatty acid metabolic process

Molecular function

\section{0 transferase activity}

0004712 protein serine/threonine/tyrosine kinase activity

0000400 four-way junction DNA binding

0005537 mannose binding

0004569 glycoprotein endo-alpha-1,2-mannosidase activity

0016627 oxidoreductase activity, acting on the $\mathrm{CH}-\mathrm{CH}$ group of donors

0033781 cholesterol 24-hydroxylase activity

1902945 metalloendopeptidase activity involved in amyloid precursor protein catabolic process

0003865 3-oxo-5-alpha-steroid 4-dehydrogenase activity

0004661 protein geranylgeranyltransferase activity

0004662 CAAX-protein geranylgeranyltransferase activity

0004915 interleukin-6 receptor activity

0004923 leukemia inhibitory factor receptor activity

0016653 oxidoreductase activity, acting on NAD $(P) H$, heme protein
GGT1,

MSMO1

CLN5

GEN1

HNRNPK

FNTA

AURKA

$A L G 10 B$

DDX11

$B A S P 1$

ALG10B,

UHMK1

AURKA, TTK

GEN1, YY1

CLN5, IGF2R

MANEA

COX15

CYP46A1

ADAM10

SRD5A1

FNTA

FNTA

IL6ST

IL6ST

c0X15 
as acceptor

0019981 interleukin-6 binding IL6ST

0045509 interleukin-27 receptor activity IL6ST

Table5. Continued

\begin{tabular}{|c|c|c|c|}
\hline GO type & GO term & Description & Overlapping gene name \\
\hline \multirow{13}{*}{$\begin{array}{l}\text { Cellular } \\
\text { component }\end{array}$} & 0000803 & Sex chromosome & SMC6 \\
\hline & 0005634 & Nucleus & $\begin{array}{l}\text { ADAM10, ANP32A, AURKA, BASP1, COA7, } \\
\text { COX15, CUTC, DDX11, DECR1, FBXL3, FGF13, } \\
\text { GJB4, GTF2H3, HNRNPK, HSPA5, NSMCE2, } \\
\text { PSMD8, RAN, RPAP2, SEPT7, SMC6, SNRPD3, } \\
\text { TMPO, TTK, UHMK1, XAF1, YY1, ZNF37A, } \\
\text { ZNF471, ZNF480, ZNF550 }\end{array}$ \\
\hline & 0005654 & Nucleoplasm & $\begin{array}{l}\text { ANP32A, ARPP19, AURKA, CUTC, DDX11, } \\
\text { DECR1, GEN1, GTF2H3, HNRNPK, NSMCE2, } \\
\text { PSMD8, RAN, RPAP2, RXYLT1, SMC6, } \\
\text { SNRPD3, UBXN8, UHMK1, VPS54, WDR19, } \\
\text { YY1, ZNF480 }\end{array}$ \\
\hline & 0005783 & Endoplasmic reticulum & $\begin{array}{l}\text { ALG10B, ANP32A, CLN5, CYP46A1, HSPA5, } \\
\text { INSIG1, LCLAT1, MAGT1, MSMO1, RCN1, } \\
\text { TECRL, UBXN8 }\end{array}$ \\
\hline & 0005789 & $\begin{array}{l}\text { Endoplasmic reticulum } \\
\text { membrane }\end{array}$ & $\begin{array}{l}\text { CYP46A1, HSPA5, INSIG1, LCLAT1, MCFD2, } \\
\text { MSMO1, PIGC, SRD5A1 }\end{array}$ \\
\hline & 0005900 & $\begin{array}{l}\text { Oncostatin-M receptor } \\
\text { complex }\end{array}$ & IL6ST \\
\hline & 0005953 & $\begin{array}{l}\text { CAAX-protein } \\
\text { geranylgeranyltransferase } \\
\text { complex }\end{array}$ & FNTA \\
\hline & 0008180 & COP9 signalosome & BASP1, HSPA5 \\
\hline & 0030496 & midbody & AURKA, DDX11, HSPA5, RAN \\
\hline & 0030915 & Smc5-Smc6 complex & NSMCE2, SMC6 \\
\hline & 0042565 & $\begin{array}{l}\text { RNA nuclear export } \\
\text { complex }\end{array}$ & $R A N$ \\
\hline & 0070069 & Cytochrome complex & $\operatorname{cox} 15$ \\
\hline & 0071598 & $\begin{array}{l}\text { Neuronal } \\
\text { ribonucleoprotein granule }\end{array}$ & UHMK1 \\
\hline
\end{tabular}

\subsection{RNA-seq analysis}

PCA results derived from the findings of performing RNA-seq analysis for all samples indicated that control and treated samples were clustered separately (Fig. 3). Therefore, it could be said that Tamoxifen 
therapy may impact on gene expression profiles at the transcriptome level among treated and control samples.

The visualization of RNA-seq analysis results derived from control and treated samples were shown in a heat map (Fig 4). It was also shown that mitochondrial respiratory genes were expressed at lower levels within treated samples compared to control ones. In current study, it was reported that MT-CO1, MT-CO3, MT-ND2, MT-ND4, MT-ND5, MT-ND6, and MT-ATP6 were the mitochondrion respiratory genes. MT-ND genes provide NADH dehydrogenase. This protein is a part of a large enzyme complex encoded by the mitochondrial genome. Moreover, the dysfunction of MT-ND proteins would lead to the electron transport chain disruption and ATP production. MT-CO genes encode Cytochrome $\mathrm{C}$ Oxidase subunits within mitochondria. It is found that they were the last enzyme in the mitochondrial electron transport chain for ATP synthesis (Kharrati-Koopaee et al., 2019). Findings derived from heat map analysis suggested that several candidate genes including ALDOA, RPL13, HSPB1, GATA3, KRT18, IGFBP4, and SULF2 were associated with the lowest gene expression level in treated samples. Aldolase (ALDOA) is known as an oncogene, which is a glycolytic enzyme that promotes the metastatic progression of cancers (Chang et al., 2019; Ji et al., 2016). It was shown that there was an association between ALDOA knock down and proliferation reduction of breast cancer cells (Zhang et al., 2017). RPL13 encodes a ribosomal protein, which is a component of $60 \mathrm{~S}$ subunit. Ribosomal proteins (RP) expression patterns were implemented as a diagnostic strategy in human cancers. Reports of several cancers indicated the dysregulation of RP expression (e.g.RPL13) (Dolezal et al., 2018); therefore, it could be said that RPL13 would be expressed at significantly higher levels in benign breast lesions compared to that of breast carcinomas (GeneCards: GC16P089674). HSPB1 is a member of heat shock proteins, which are considered as a large family of proteins with breast cancer behavior (Zoppino et al., 2018). It was reported that the down-regulation of HSPB1 protein may induce the expression of phosphatase and tensin homologue (PTEN) as a tumor suppressor gene. In other words, PTEN stabilization depends upon HSPB1 low-level expression (CayadoGutiérrez et al., 2013).

GATA binding protein 3 (GATA3) is a highly conserved transcription factor that belongs to GATA family and leads to the expression of a large number of important genes (Voduc.et al., 2008). Furthermore, it contributes to the human growth and differentiation cells including the mammary tissue. Lower levels of GATA3 expression in breast tumors are associated with larger tumors. Therefore, GATA3 is considered as an important gene in breast cancer development; however, its exact role as an oncogene or tumor suppressor is unclear (Afzaljavan.et al., 2021; Takaku.et al., 2015). Keratin 18 (KRT18) is a member of the intermediate filament family of cytoskeletal protein that is involved in the tissue integrity, and its overexpression has been reported in many cancers (Zhang et al., 2019). It was also reported that $K T 18$ was over-expressed in breast cancer and played a vital role in the breast tumorigenesis and tumor dedifferentiation (HA et al., 2011). Insulin-like growth factor binding proteins (IGFBPS) would regulate many cellular processes such as cell proliferation. IGFBPs act as binding proteins for insulin-like growth factor (IGF); furthermore, it is evidenced that they play a critical role in the cancer progression, especially in breast cancer (Hermani.et al., 2013). However, there are various reports regarding their activities as oncogenes or tumor suppressors. IGFBP5 may be considered as an oncogene due to its contribution to 
metastasis, proliferation, and limited responses to endocrine treatment; also, it acts as a tumor suppressor because of its apoptotic role, anti-metastatic function, and anti-migratory effects (Akkiprik et al., 2015)

Sulfatase family, which includes sulfatase1 (SULF1) and sulfatase 2 (SULF2), plays an important role in the multiple biological pathways through regulating the sulfation status (Jiang.et.al, 2020). It was confirmed that SULF2 would promote the breast cancer progression and regulate the tumor-related genes expression in breast cancer (Zhu.et.al, 2016).

Results of the whole transcriptome analysis showed that there were 21515 DGEs among control and treated samples, while findings of Volcano plot indicated that most of DGEs were classified as the downregulated genes. At significant levels $\left(P<0.01,-\log _{10}(P\right.$-value $\left.)>2\right)$, there were 910 and 3 candidate genes reported as the significant down- and up-regulated ones (Fig.5).

Results of Volcano plot showed that three candidate genes including GREB1, EGR3, and XAF1 were clustered as the up-regulated genes. It was also found that the estrogen-based growth regulation in breast cancer 1 (GREB1) was an early estrogen-responsive gene, and there was a close association between GREB1 expression and estrogen levels in breast cancer patients. In fact, GREB1 was an ESR1 (estrogen receptor 1) that could mediate the estrogen action. It was reported that the optimal level of GREB1 expression was required for breast cancer cells proliferation (Cheng.et al, 2018). However, GREB1 knockdown could prevent the breast cancer cell lines proliferation; therefore, it was found that targeting GREB1 could provide a possible treatment strategy through inhibiting the tumor-promoting pathways (Hodgkinson.et al., 2018). Early growth response (EGR) is a family of transcription factors that contributes to various biological pathways (Pio.et al., 2013). It was reported that $E G R 3$ could be induced by estrogen in breast cancer MCF-7 cells and consequently, become involved in the estrogen-signaling pathway (Inoue.et al., 2004). Moreover, EGR3 levels were significantly higher within tissue samples derived from patients with recurrent breast cancer compared to those with primary tumors (Knudsen.et al., 2020). XIAP-associated factor 1 (XAF1) is a tumor suppressor observed in the multiple human neoplasms (Shin et al., 2017). It was shown that XAF1 loss expression would be resulted from tumor staging and its dysfunction was associated with tumor progression. Moreover, its appropriate expression could play a critical role in the apoptosis inductions and tumor growth inhibition in the gastric cancer (Tu.et al., 2009). Pinto.et al. (2020) reported that XAF1 may be considered as a TP53 function modifier through increasing the transcriptional activity of hypomorphic TP53 variants. TP53 is one of the most significant tumor suppressor genes, which is commonly mutated in various cancers such as breast cancer (Børresen-Dale, 2003).

It is noteworthy that $P R O M 1, F B N 2$, and $K L H L 14$ were highly down-regulated (Fig.5). Prominin 1 (PROM1orCD133) is known as a biomarker of cancer stem cells; however, its biological role is not illustrated perfectly (Saha et al., 2020). Findings showed that there was an association between PROM1 levels and malignancy properties stages including initiation, progression, and metastasis. Moreover, it was reported that PROM1 would contribute to the cell motility and invasion, and may affect the 
malignancy of breast tumors. Also, PROM1 genes were highly expressed in TNBC cell lines (Brugnoli et al., 2019; Guo et al., 2017). Fibrillin-2 (FBN2) is an extracellular calcium-binding microfibril that contributes to several biological pathways including the bone mineralization, osteoblast maturation, and calcium binding (UniProtKB: P35556). FBN2 is considered as a biomarker of cancers early diagnosis. For example, Promotor hypermethylation of $F B N 2$ is associated with colorectal cancer as an early event. In fact, Methylation may lead to FBN2 down-regulation in primary tumors (Yi.et al., 2012), while Kelch-like protein 14 (KLHL 14) belongs to Kelch family genes and interacts with torsin-1 A (UniProtKB: Q9P2G3). It was shown that $K L H L 14$ was significantly overexpressed in breast cancer compared to normal breast tissues, and had a positive relationship with tumor aggressiveness (Fritzsche.et al, 2006). Moreover, findings indicated the vital role of KLHL14 in the development of various cancers including ovarian cancer (Chen.et.al, 2020).

Results derived from GO enrichment analysis of DGEs showed that most of DGEs were enriched in the regulations of apoptosis and cell death pathways (Table 6). Cell cycle damage is considered as the main cause of cancer incidence; therefore, the balance between proliferation and cell death is disrupted in cancers (Robert and David, 2005). It was shown that apoptosis inactivation would play a vital role in the process of cancer development (Brown and Attardi, 2005). Therefore, it could be said that significant GO term of apoptosis pathways could contribute to cancerous cell death under Tamoxifen therapy. Proteolysis is a hydrolysis reaction that occurs when peptide bonds and proteins are broken down into smaller polypeptides or amino acids. There is an association between the metastasis of malignancy tumor and overexpression of proteolytic enzyme. More importantly, proteolysis inactivation in cancerous tissue plays a critical role in the inhibition of tumor invasion, angiogenesis, and migration (Wyganowska-Świątkowska et al., 2019). Interestingly, our findings suggested that negative proteolysis regulation and consequent regulations of proteolytic pathways could be regarded as considerable GO terms that control the cancer under Tamoxifen treatment (Table 6).

Table6. Results of GO enrichment analysis of DGEs 


\begin{tabular}{|c|c|c|c|c|c|}
\hline GO type & GO term & $\begin{array}{l}\text { Reference } \\
\text { genes in } \\
\text { category }\end{array}$ & Description & $\begin{array}{l}\text { DGEs } \\
\text { count }\end{array}$ & Gene names \\
\hline \multirow[t]{9}{*}{$\begin{array}{l}\text { Biological } \\
\text { process }\end{array}$} & 0051248 & 20 & $\begin{array}{l}\text { Negative regulation } \\
\text { of protein metabolic } \\
\text { process }\end{array}$ & 8 & $\begin{array}{l}\text { CTSZ, GPX1, GSTP1, } \\
\text { IGFBP3, ITM2C, MAGEA2, } \\
\text { MAGEA3, MECOM }\end{array}$ \\
\hline & 0010941 & 30 & $\begin{array}{l}\text { Regulation of cell } \\
\text { death }\end{array}$ & 10 & $\begin{array}{l}\text { CTSZ, GPX1, GSTP1, } \\
\text { IGFBP } 3, M A G E A 3, M A L T 1, \\
\text { MECOM, MSX1, PAX8, } \\
\text { TRIM2 }\end{array}$ \\
\hline & 0030162 & 6 & $\begin{array}{l}\text { Regulation of } \\
\text { proteolysis }\end{array}$ & 4 & $\begin{array}{l}\text { CTSZ, GPX1, MAGEA3, } \\
\text { MALT1 }\end{array}$ \\
\hline & 0032269 & 17 & $\begin{array}{l}\text { Negative regulation } \\
\text { of cellular protein } \\
\text { metabolic process }\end{array}$ & 7 & $\begin{array}{l}\text { CTSZ, GPX1, GSTP1, } \\
\text { IGFBP3, MAGEA2, } \\
\text { MAGEA3, MECOM }\end{array}$ \\
\hline & 0043281 & 4 & $\begin{array}{l}\text { Regulation of } \\
\text { cysteine-type } \\
\text { endopeptidase } \\
\text { activity involved in } \\
\text { apoptotic process }\end{array}$ & 7 & GPX1, MAGEA3, MALT1 \\
\hline & 0045861 & 4 & $\begin{array}{l}\text { Negative regulation } \\
\text { of proteolysis }\end{array}$ & 3 & CTSZ, GPX1, MAGEA3 \\
\hline & 0052548 & 4 & $\begin{array}{l}\text { Regulation of } \\
\text { endopeptidase } \\
\text { activity }\end{array}$ & 3 & GPX1, MAGEA3, MALT1 \\
\hline & 2000116 & 4 & $\begin{array}{l}\text { Regulation of } \\
\text { cysteine-type } \\
\text { endopeptidase } \\
\text { activity }\end{array}$ & 3 & GPX1, MAGEA3, MALT1 \\
\hline & 0043067 & 29 & $\begin{array}{l}\text { Regulation of } \\
\text { programmed cell } \\
\text { death }\end{array}$ & 9 & $\begin{array}{l}\text { GPX1, GSTP1, IGFBP3, } \\
\text { MAGEA3, MALT1, MECOM, } \\
\text { MSX1, PAX8, TRIM2 }\end{array}$ \\
\hline \multirow[t]{2}{*}{$\begin{array}{l}\text { Molecular } \\
\text { function }\end{array}$} & 0019904 & 12 & $\begin{array}{l}\text { Protein domain } \\
\text { specific binding }\end{array}$ & 5 & $\begin{array}{l}\text { CCN1, CXADR, GPX1, } \\
\text { SCNN1A, TCEAL9 }\end{array}$ \\
\hline & 0004602 & 2 & $\begin{array}{l}\text { Glutathione } \\
\text { peroxidase activity }\end{array}$ & 2 & GPX1, GSTP1 \\
\hline \multirow[t]{2}{*}{$\begin{array}{l}\text { Cellular } \\
\text { component }\end{array}$} & 0070062 & 49 & Extracellular exosome & 14 & $\begin{array}{l}\text { ACSL4, AKR1B1, } \\
\text { CRISPLD1, CTSZ, FSTL1, } \\
\text { GREB1, GSTP1, IGFBP7, } \\
\text { ITM2C, LDHB, MSN, } \\
\text { PSAT1, RAB34, SCNN1A }\end{array}$ \\
\hline & 0043230 & 50 & $\begin{array}{l}\text { Extracellular } \\
\text { organelle }\end{array}$ & 14 & $\begin{array}{l}\text { ACSL4, AKR1B1, } \\
\text { CRISPLD1, CTSZ, FSTL1, } \\
\text { GREB1, GSTP1, IGFBP7, } \\
\text { ITM2C, LDHB, MSN, } \\
\text { PSAT1, RAB34, SCNN1A }\end{array}$ \\
\hline
\end{tabular}




\begin{tabular}{|c|c|c|c|c|}
\hline 1903561 & 50 & Extracellular vesicle & 14 & $\begin{array}{l}\text { ACSL4, AKR1B1, } \\
\text { CRISPLD1, CTSZ, FSTL1 } \\
\text { GREB1, GSTP1, IGFBP7, } \\
\text { ITM2C, LDHB, MSN, } \\
\text { PSAT1, RAB34, SCNN1A }\end{array}$ \\
\hline 0044432 & 28 & $\begin{array}{l}\text { Endoplasmic } \\
\text { reticulum part }\end{array}$ & 9 & $\begin{array}{l}\text { ACSL4, COL9A2, CTSZ, } \\
\text { FADS2, FSTL1, GJA1, } \\
\text { IGFBP3, IGFBP7, RCN1 }\end{array}$ \\
\hline
\end{tabular}

\section{Discussion}

Generally, breast cancer tumors are hormone receptor-positive with highly estrogen- and progesteronedependent growth rates. Tamoxifen is a type of hormonal therapy implemented with the purpose of treating the estrogen receptor-positive breast cancer; also, it can decrease the risk of invasive cancer development. However, it is able to affect the gene expression profile at transcriptome level (Taylor et al., 2010). Furthermore, the activated form of it could bind to DNA and act as a mutagen factor (Brown, 2009); therefore, it may impact on the drug response process through the alteration of genetic variants. To confirm this idea, Chan et al. (2016) showed that the genetic alteration of variants would contribute to drug response and provide a new insight about pharmacogenomics implication. Therefore, it could be said that Tamoxifen consumption may lead to several biological pathways that can increase or decrease the chances of survival and effective treatments. Results achieved from RNA-seq analysis in MCF7 cell line under Tamoxifen therapy revealed that there were several candidate genes and biological pathways that could result in the tumor suppression and consequently, effective treatments. XIAP-associated factor $1(X A F 1)$ can be up-regulated under Tamoxifen therapy; also, it is a tumor suppressor that plays a critical role in the apoptosis induction and tumor growth inhibition in gastric cancer (Tu.et.al, 2009). Interestingly, it was reported that the combination of XAF1 with TP53 would act as a modifier. TP53 is a key tumor suppressor gene, which is generally mutated in various cancers such as breast cancer (Børresen-Dale, 2003; Pinto et al., 2020). It was found in current study that PROM1 and KLHL14 were down-regulated under hormone therapy; also, an association was observed between PROM1 levels and malignancy features including initiation, progression, and metastasis. Results showed that PROM1 led to the cell motility and invasion and may impact on the breast tumors malignancy (Brugnoli et al, 2019; Guo.et al, 2017). It was observed that there was a high level of $K L H L 14$ expression in breast cancer compared to the normal breast tissues, which was associated with considerable tumor aggressiveness (Fritzsche.et.al, 2006). KLHL 14 also played a vital role in the development of various cancers such as ovarian cancer (Chen et al., 2020), and results derived from GO enrichment analysis of DGEs indicated that most of DGEs could considerably result in the cell death, apoptosis, and negative regulation of proteolysis process. Generally, apoptosis has a critical role in the inhibition of cancerous cell growth.

Proteolysis activation in cancerous tissues would result in the tumor invasion (Wyganowska-Świątkowska et al., 2019; Brown and Attardi, 2005). All of the above-mentioned findings were in accordance with those of Rouhimoghadam et al. (2018) who showed that tamoxifen treatment on the breast cancer MCF-7 cell line could lead to the apoptosis induction through activating the 
apoptotic signaling pathways including Tp53 and MAPKs. Comparable results reported that Tamoxifen induced the apoptosis through inhibiting the cancerous inhibitor of protein phosphatase 2A (CIP2A) and phospho-Akt (p-Akt) in ER-negative breast cancer cell lines (Liu et al., 2014). Frasor et al. (2006) also reported that Tamoxifen could regulate the gene expression in breast cancer cells and indicated several Tamoxifen-regulated candidate genes including SOCS1 and IEX-1, which was in accordance with our findings. Cytokine Signaling 1 (SOCS1) suppressor is considered as a tumor suppressor that plays a negative regulatory role for cytokine action through JAK/STAT pathway and suppresses the growth of hepatocellular carcinomas. IEX-1, which is an immediate early response gene that can widely be expressed in various tissues, is overexpressed in breast cancer cells and has an inhibitory effect on breast cancer cell proliferation. Generally, it could be concluded that Tamoxifen implementation in the treatment procedures could be beneficial at the transcriptome level; however, it may induce the oncogene expression in rodent uterine (Nephew et al., 1996).

Our hypothesis regarding Tamoxifen mutagenicity effect and its role in the drug response was not approved appropriately. It was found that most of the candidate genes with differential genetic variants had dual roles as oncogenes or tumor suppressors; however, their exact contribution in breast cancer has not been investigated precisely.

For example, findings of the genetic variant analysis revealed that differential genetic variants between control and treated samples (under Tamoxifen therapy) were overlapped with NSMCE2 and DDX11 candidate genes. NSMCE2 contributes to DNA repair pathway and acts as a cancer suppressor in mice (Jacome.et.al, 2015). DDX11 is a member of helicase family, which involves in DNA replication pathways; however, its role in cancer has not been investigated precisely. DNA helicases may have a tumor suppressor function in cancers (Mahtab.et.al, 2021).

It was revealed by $\mathrm{GO}$ analysis that reported differential genetic variants were associated with FNTA, HSPA5, IL-6, and AURKA candidate genes. FTase enzyme (FNTA) could lead to the tumor progression and abnormal copy numbers of FNTA were associated with pathological changes of breast cancer (Tian.et.al, 2020). HSPA5 (Heat-shock protein 5) promoted the drug resistance and metastasis (Chang et al., 2014), while Interleukin-6 (IL-6) contributed to the expansion and differentiation of tumor cells (Masjedi et al., 2018). AURKA gene was associated with potential cancer susceptibility and became involved in the cell cycle progression regulation (Cox et al., 2006).

\section{Conclusion}

Results of current study that was carried out at transcriptome level showed that Tamoxifen consumption in MCF7 cell line could be associated with candidate genes and biological pathways that contribute to the apoptosis, proteolysis, and tumor suppression. Moreover, Tamoxifen could decrease the expression of candidate genes involved in tumor progression, invasion, and metastasis. The mutagenicity effect of Tamoxifen and its contribution to alterations of genetic variants was not confirmed perfectly. Therefore, it 
was suggested that Tamoxifen could not have any significant role in an effective treatment through changing the genetic variants profile.

\section{Abbreviations}

EBI

European Bioinformatics Institution

SNV

single nucleotide variation

MNV

multi nucleotide variation

MCF7

Michigan Cancer Foundation-7

DDX11

DEAD/H-Box Helicase 11

DGES

differential gene expressions

MT-CO1

Mitochondrially Encoded Cytochrome C Oxidase I

MT-CO3

Mitochondrially Encoded Cytochrome C Oxidase III

MT-ND2

Mitochondrially Encoded NADH:Ubiquinone Oxidoreductase Core Subunit 2 MT-ND4

Mitochondrially Encoded NADH:Ubiquinone Oxidoreductase Core Subunit 4 MT-ND5

Mitochondrially Encoded NADH:Ubiquinone Oxidoreductase Core Subunit 5 MT-ND6

Mitochondrially Encoded NADH:Ubiquinone Oxidoreductase Core Subunit 6 MT-ATP6

Mitochondrially encoded ATP synthase membrane subunit 6

ALDOA

Aldolase

RPL13

Ribosomal Protein L13

HSPB1

Heat shock protein beta-1

PTEN

phosphatase and tensin homologue

KRT18 
Keratin 18

GATA3

GATA binding protein 3

IGFBPs

Insulin-like growth factor binding proteins

IGF

Insulin-like growth factor

SULF1

Sulfatase1

SULF2

Sulfatase 2

GREB1

Growth regulation in breast cancer 1

ESR1

Estrogen receptor 1

EGR

Early growth response

XAF1

XIAP-associated factor 1

PROM1

XIAP-associated factor 1

TNBC

Triple-negative Breast Cancer

KLHL14

Kelch-like protein 14

FBN2

Fibrillin-2

FNTA

FTase enzyme

HSPA5

Heat-shock protein 5

IL-6

Interleukin-6

GEN1

Flap endonuclease GEN homolog 1

AURKA

Aurora Kinase A

BRCA1

Breast cancer type 1

BRCA1 
Breast cancer type 2

coX15

cytochrome C Oxidase subunit 15

\section{Declarations}

Ethics approval and consent to participate

Not applicable

Consent for publication

Not applicable

\section{Availability of data and materials}

The datasets analyzed during the current study are available in the European Bioinformatics Institution (EBI) repository (Table1).

\section{Conflict of interest}

The authors declare no conflict of interest.

\section{Funding}

Current study was financially supported by National Institute for Medical Research Development (NIMAD, grant number: 982563).

\section{Author's contributions}

HKK, MNC and STH conceived the study. HKK contributed to data analysis and prepared the primary draft of manuscript. $A D, M D$, and $K B L$ revised the manuscript. All authors read and approve the manuscript.

\section{Acknowledgments}

Not applicable

\section{References}

1. Abo-Touk NA, Sakr HA, Abd El-Lattef ATIF. Switching to letrozole versus continued tamoxifen therapy in treatment of postmenopausal women with early breast cancer. J Egypt Natl Canc Inst. 2010;22(1):79-85.

2. Afzaljavan F, Sadr AS, Savas S, Pasdar A. GATA3 somatic mutations are associated with clinicopathological features and expression profile in TCGA breast cancer patients. Scientific reports. 2021;11(1):1-13. 
3. Akkiprik M, Peker I, Özmen T, Amuran GG, Güllüoğlu BM, Kaya H, Özer A. Identification of differentially expressed IGFBP5-related genes in breast cancer tumor tissues using CDNA microarray experiments. Genes. 2015;6(4):1201-14.

4. Akram M, lqbal M, Daniyal M, Khan AU. Awareness and current knowledge of breast cancer. Biological research. 2017;50(1):1-23.

5. AlFakeeh A, Brezden-Masley C. Overcoming endocrine resistance in hormone receptor-positive breast cancer. Current Oncology. 2018;25(s1):18-27.

6. Bachtiar M, Lee CG. Genetics of population differences in drug response. Current Genetic Medicine Reports. 2013;1(3):162-70.

7. Børresen-Dale AL. TP53 and breast cancer. Hum Mutat. 2003;21(3):292-300.

8. Brown JM, Attardi LD. The role of apoptosis in cancer development and treatment response. Nature reviews cancer. 2005;5(3):231-7.

9. Brown K. Is tamoxifen a genotoxic carcinogen in women? Mutagenesis. 2009;24(5):391-404.

10. Brugnoli F, Grassilli S, Al-Qassab Y, Capitani S, Bertagnolo V. (2019). CD133 in breast cancer cells: more than a stem cell marker. Journal of oncology, 2019.

11. Cayado-Gutiérrez, N., Moncalero, V. L., Rosales, E. M., Berón, W., Salvatierra, E.E., Alvarez-Olmedo, D., ... Ciocca, D. R. (2013). Downregulation of Hsp27 (HSPB1) in MCF-7 human breast cancer cells induces upregulation of PTEN. Cell Stress and Chaperones, 18(2), 243-249.

12. Cox DG, Hankinson SE, Hunter DJ. Polymorphisms of the AURKA (STK15/Aurora Kinase) gene and breast cancer risk (United States). Cancer Causes Control. 2006;17(1):81-3.

13. Chan, S. L., Samaranayake, N., Ross, C. J., Toh, M. T., Carleton, B., Hayden, M. R.,... Brunham, L. R. (2016). Genetic diversity of variants involved in drug response and metabolism in Sri Lankan populations: implications for clinical implementation of pharmacogenomics. Pharmacogenetics and genomics, 26(1), 28.

14. Chang, Y. C., Chiou, J., Yang, Y. F., Su, C. Y., Lin, Y. F., Yang, C. N., ... Hsiao,M. (2019). Therapeutic targeting of aldolase a interactions inhibits lung cancer metastasis and prolongs survival. Cancer research, 79(18), 4754-4766.

15. Chang, Y. W., Tseng, C. F., Wang, M. Y., Chang, W. C., Lee, C. C., Chen, L. T., ...Su, J. L. (2016). Deacetylation of HSPA5 by HDAC6 leads to GP78-mediated HSPA5 ubiquitination at K447 and suppresses metastasis of breast cancer. Oncogene, 35(12), 1517-1528.

16. Chen Z, Wu M, Liu J. Kelch-like protein 14 promotes proliferation and migration of ovarian cancer cells. International Journal of Clinical Experimental Pathology. 2020;13(12):2950.

17. Cheng M, Michalski S, Kommagani R. Role for growth regulation by estrogen in breast cancer 1 (GREB1) in hormone-dependent cancers. Int J Mol Sci. 2018;19(9):2543.

18. Davies R, Oreffo VI, Martin EA, Festing MF, White IN, Smith LL, Styles JA. Tamoxifen causes gene mutations in the livers of lambda/lacl transgenic rats. Cancer research. 1997;57(7):1288-93. 
19. Doan R, Cohen ND, Sawyer J, Ghaffari N, Johnson CD, Dindot SV. Whole-genome sequencing and genetic variant analysis of a Quarter Horse mare. BMC Genomics. 2012;13(1):1-12.

20. Dolezal JM, Dash AP, Prochownik EV. Diagnostic and prognostic implications of ribosomal protein transcript expression patterns in human cancers. BMC Cancer. 2018;18(1):1-14.

21. Esfandiari P, Dadpasand M, Kharrati-Koopaee H, Atashi H, Gharghi A, Niazi A. Bioinformatics, phylogenetic and variant association analysis of Ovocalyxin-32 gene reveals its contribution to egg production traits in native chickens. Animal Gene. 2020;17:200108.

22. Eterno, V., Zambelli, A., Villani, L., Tuscano, A., Manera, S., Spitaleri, A., ... Amato,A. (2016). AurkA controls self-renewal of breast cancer-initiating cells promoting wnt3a stabilization through suppression of miR-128. Scientific reports, 6(1), 1-13.

23. Frasor, J., Chang, E. C., Komm, B., Lin, C. Y., Vega, V. B., Liu, E. T., ... Katzenellenbogen,B. S. (2006). Gene expression preferentially regulated by tamoxifen in breast cancer cells and correlations with clinical outcome. Cancer research, 66(14), 7334-7340.

24. Fekete JT, Győrffy B. ROCplot. org: Validating predictive biomarkers of chemotherapy/hormonal therapy/anti-HER2 therapy using transcriptomic data of 3,104 breast cancer patients. International journal of cancer. 2019;145(11):3140-51.

25. Gao L, Shen K, Yin N, Jiang M. Comprehensive transcriptomic analysis reveals dysregulated competing endogenous RNA network in endocrine resistant breast cancer cells. Frontiers in oncology. 2020;10:2590.

26. Gao SP, Sun HF, Fu WY, Li LD, Zhao Y, Chen MT, Jin W. High expression of COX5B is associated with poor prognosis in breast cancer. Future Oncol. 2017;13(19):1711-9.

27. Gerl R, Vaux DL. Apoptosis in the development and treatment of cancer. Carcinogenesis. 2005;26(2):263-70.

28. Geisler J, Sasano H, Chen S, Purohit A. Steroid sulfatase inhibitors: promising new tools for breast cancer therapy? J Steroid Biochem Mol Biol. 2011;125(1-2):39-45.

29. Guénard F, Labrie Y, Ouellette G, Beauparlant CJ, Durocher F. Genetic sequence variations of BRCA1interacting genes AURKA, BAP1, BARD1 and DHX9 in French Canadian families with high risk of breast cancer. Journal of human genetics. 2009;54(3):152-61.

30. Guo J, Gong G, Zhang B. Screening and identification of potential biomarkers in triple-negative breast cancer by integrated analysis. Oncol Rep. 2017;38(4):2219-28.

31. Ha, S. A., Lee, Y. S., Kim, H. K., Yoo, J., Kim, S., Gong, G. H., ... Kim, J. W. (2012). The prognostic potential of keratin 18 in breast cancer associated with tumor dedifferentiation,and the loss of estrogen and progesterone receptors. Cancer Biomarkers, 10(5), 219-231.

32. Hermani A, Shukla A, Medunjanin S, Werner H, Mayer D. Insulin-like growth factor binding protein-4 and-5 modulate ligand-dependent estrogen receptor-a activation in breast cancer cells in an IGFindependent manner. Cellular signalling. 2013;25(6):1395-402.

33. Hodgkinson K, Forrest LA, Vuong N, Garson K, Djordjevic B, Vanderhyden BC. GREB1 is an estrogen receptor-regulated tumour promoter that is frequently expressed in ovarian cancer. Oncogene. 
2018;37(44):5873-86.

34. Jacome, A., Gutierrez-Martinez, P., Schiavoni, F., Tenaglia, E., Martinez, P., Rodríguez-Acebes,S., ... Fernandez-Capetillo, O. (2015). NSMCE 2 suppresses cancer and aging in mice independently of its SUMO ligase activity. The EMBO journal, 34(21), 2604-2619.

35. Ji, S., Zhang, B., Liu, J., Qin, Y., Liang, C., Shi, S., ... Yu, X. (2016). ALDOA functions as an oncogene in the highly metastatic pancreatic cancer. Cancer letters, 374(1), 127-135.

36. Jia R, Weng Y, Li Z, Liang W, Ji Y, Liang Y, Ning P. (2021). Bioinformatics Analysis Identifies IL6ST as a Potential Tumor Suppressor Gene for Triple-Negative Breast Cancer. Reproductive Sciences, 1-11.

37. Jiang T, Chen ZH, Chen Z, Tan D. (2020). SULF2 promotes tumorigenesis and inhibits apoptosis of cervical cancer cells through the ERK/AKT signaling pathway. Brazilian Journal of Medical and Biological Research, 53.

38. Inoue A, Omoto Y, Yamaguchi Y, Kiyama R, Hayashi SI. Transcription factor EGR3 is involved in the estrogen-signaling pathway in breast cancer cells. J Mol Endocrinol. 2004;32(3):649-61.

39. Ismail T, Lee HK, Kim C, Kwon T, Park TJ, Lee HS. KDM1A microenvironment, its oncogenic potential, and therapeutic significance. Epigenetics chromatin. 2018;11(1):1-15.

40. Knudsen, A. M., Eilertsen, I., Kielland, S., Pedersen, M. W., Sørensen, M. D., Dahlrot,R. H., ... Kristensen, B. W. (2020). Expression and prognostic value of the transcription factors EGR1 and EGR3 in gliomas. Scientific reports, 10(1), 1-13.

41. Kharrati KH, Mohammadabadi MR, Kharrati TARANG,A, K. M., \& Esmailizadeh KA. (2012). Study of the association between the allelic variations in DGAT1 gene with mastitis in Iranian Holstein cattle.

42. Kharrati-Koopaee H, Ebrahimie E, Dadpasand M, Niazi A, Esmailizadeh A. Genomic analysis reveals variant association with high altitude adaptation in native chickens. Scientific reports. 2019;9(1):122.

43. Koopaee HK, Koshkoiyeh AE. SNPs Genotyping technologies and their applications in farm animals breeding programs. Brazilian Archives of Biology Technology. 2014;57:87-95.

44. Kumari K, Keshari S, Sengupta D, Sabat SC, Mishra SK. Transcriptome analysis of genes associated with breast cancer cell motility in response to Artemisinin treatment. BMC Cancer. 2017;17(1):1-13.

45. Liao Y, Liao Y, Li J, Li J, Fan Y, Xu B. Polymorphisms in AURKA and AURKB are associated with the survival of triple-negative breast cancer patients treated with taxane-based adjuvant chemotherapy. Cancer management research. 2018;10:3801.

46. Lanceta, L., O'Neill, C., Lypova, N., Li, X., Rouchka, E., Waigel, S., ... Imbert-Fernandez,Y. (2020). Transcriptomic profiling identifies differentially expressed genes in palbociclib-resistant ER + MCF7 breast cancer cells. Genes, 11(4), 467.

47. Liapis E, McLuckie K, Lewis P, Farmer P, Brown K. (2008). Mutagenicity of tamoxifen induced DNA damage in human endometrial cells and in silico prediction of p53 mutation hotspots.

48. Liu, C. Y., Hung, M. H., Wang, D. S., Chu, P. Y., Su, J. C., Teng, T. H., ... Chen,K. F. (2014). Tamoxifen induces apoptosis through cancerous inhibitor of protein phosphatase $2 \mathrm{~A}$-dependent phospho-Akt 
inactivation in estrogen receptor-negative human breast cancer cells. Breast cancer research, 16(5), $1-15$.

49. Madian AG, Wheeler HE, Jones RB, Dolan ME. Relating human genetic variation to variation in drug responses. Trends in genetics. 2012;28(10):487-95.

50. Mahtab M, Boavida A, Santos D, Pisani FM. The Genome Stability Maintenance DNA Helicase DDX11 and Its Role in Cancer. Genes. 2021;12(3):395.

51. Mathe A, Wong-Brown M, Morten B, Forbes JF, Braye SG, Avery-Kiejda KA, Scott RJ. Novel genes associated with lymph node metastasis in triple negative breast cancer. Scientific reports. 2015;5(1):1-13.

52. Moiseenko F, Volkov N, Bogdanov A, Dubina M, Moiseyenko V. (2017). Resistance mechanisms to drug therapy in breast cancer and other solid tumors: An opinion. F1000Research, 6.

53. Mortazavi A, Williams BA, McCue K, Schaeffer L, Wold B. Mapping and quantifying mammalian transcriptomes by RNA-SEq. Nature methods. 2008;5(7):621-8.

54. Nephew KP, Polek TC, Khan SA. Tamoxifen-induced proto-oncogene expression persists in uterine endometrial epithelium. Endocrinology. 1996;137(1):219-24.

55. Pond KW, de Renty C, Yagle MK, Ellis NA. Rescue of collapsed replication forks is dependent on NSMCE2 to prevent mitotic DNA damage. PLoS Genet. 2019;15(2):e1007942.

56. Pinto, E. M., Figueiredo, B. C., Chen, W., Galvao, H. C., Formiga, M. N., Fragoso,M. C. B., ... Zambetti, G. P. (2020). XAF1 as a modifier of p53 function and cancer susceptibility. Science Advances, 6(26), eaba3231.

57. Pio R, Jia Z, Baron VT, Mercola D, UCI NCI SPECS consortium of the Strategic Partners for the Evaluation of Cancer Signatures, Prostate Cancer. Early growth response 3 (Egr3) is highly overexpressed in non-relapsing prostate cancer but not in relapsing prostate cancer. PloS one. 2013;8(1):e54096.

58. Redmond, A. M., Byrne, C., Bane, F. T., Brown, G. D., Tibbitts, P., O’Brien, K., ...Young, L. S. (2015). Genomic interaction between ER and HMGB2 identifies DDX18 as a novel driver of endocrine resistance in breast cancer cells. Oncogene, 34(29), 3871-3880.

59. Rouhimoghadam M, Safarian S, Carroll JS, Sheibani N, Bidkhori G. Tamoxifen-induced apoptosis of MCF-7 cells via GPR30/PI3K/MAPKs interactions: verification by ODE modeling and RNA sequencing. Frontiers in physiology. 2018;9:907.

60. Saha SK, Islam SR, Kwak KS, Rahman MS, Cho SG. PROM1 and PROM2 expression differentially modulates clinical prognosis of cancer: a multiomics analysis. Cancer Gene Ther. 2020;27(3):14767.

61. Selli C, Dixon JM, Sims AH. Accurate prediction of response to endocrine therapy in breast cancer patients: current and future biomarkers. Breast Cancer Res. 2016;18(1):1-10.

62. Shin CH, Lee MG, Han J, Jeong SI, Ryu BK, Chi SG. (2017). Identification of XAF1-MT2A mutual antagonism as a molecular switch in cell-fate decisions under stressful conditions. Proceedings of the National Academy of Sciences, 114(22), 5683-5688. 
63. Sjöström, M., Chang, S. L., Fishbane, N., Davicioni, E., Hartman, L., Holmberg, E.,... Karlsson, P. (2020). Comprehensive transcriptomic profiling identifies breast cancer patients who may be spared adjuvant systemic therapy. Clinical Cancer Research, 26(1), 171-182.

64. Szostakowska M, Trębińska-Stryjewska A, Grzybowska EA, Fabisiewicz A. Resistance to endocrine therapy in breast cancer: molecular mechanisms and future goals. Breast Cancer Res Treat. 2019;173(3):489-97.

65. Staff S, Isola J, Jumppanen M, Tanner M. Aurora-A gene is frequently amplified in basal-like breast cancer. Oncol Rep. 2010;23(2):307-12.

66. Sun L, Zhang Y, Pan Z, Li B, Sun M, Zhang X. Expression and Localization of GEN1 in Mouse Mammary Epithelial Cells. J Biochem Mol Toxicol. 2014;28(10):450-5.

67. Takaku M, Grimm SA, Wade PA. GATA3 in breast cancer: tumor suppressor or oncogene? Gene Expr. 2015;16(4):163.

68. Taylor, K. J., Sims, A. H., Liang, L., Faratian, D., Muir, M., Walker, G., ... Langdon,S. P. (2010). Dynamic changes in gene expression in vivo predict prognosis of tamoxifen-treated patients with breast cancer. Breast Cancer Research, 12(3), 1-13.

69. Tian J, Fan J, Xu J, Ren T, Guo H, Zhou L. circFNTA accelerates proliferation and invasion of bladder cancer. Oncology letters. 2020;19(1):1017-23.

70. Tu, S. P., Liston, P., Cui, J. T., Lin, M. C., Jiang, X. H., Yang, Y., ... Wong, B.C. Y. (2009). Restoration of XAF1 expression induces apoptosis and inhibits tumor growth in gastric cancer. International journal of cancer, 125(3), 688-697.

71. Turnbull, C., Hines, S., Renwick, A., Hughes, D., Pernet, D., Elliott, A., ... Rahman,N. (2010). Mutation and association analysis of GEN1 in breast cancer susceptibility.Breast cancer research and treatment, 124(1), 283-288.

72. Voduc D, Cheang M, Nielsen T. GATA-3 expression in breast cancer has a strong association with estrogen receptor but lacks independent prognostic value. Cancer Epidemiology Prevention Biomarkers. 2008;17(2):365-73.

73. Wardell SE, Norris JD, McDonnell DP. Breast Cancer: Targeting mutant estrogen receptors. Elife. 2019;8:e44181.

74. White IN, Smith LL. Mechanisms of Tamoxifen-Induced Genotoxicity and Carcinogenicity. In: Hormonal Carcinogenesis II. New York: Springer; 1996. pp. 228-39.

75. Wu Y, Qian Y, Zhou G, Lv J, Yan Q, Dong X. Effect of GEN1 interference on the chemosensitivity of the breast cancer MCF7 and SKBR3 cell lines. Oncology letters. 2016;11(6):3597-604.

76. WyganowskaŚwiątkowska M, Tarnowski M, Murtagh D, SkrzypczakJankun E, Jankun J. Proteolysis is the most fundamental property of malignancy and its inhibition may be used therapeutically. Int $J$ Mol Med. 2019;43(1):15-25.

77. Yi, J. M., Dhir, M., Guzzetta, A. A., lacobuzio-Donahue, C. A., Heo, K., Yang, K.M., ... Ahuja, N. (2012). DNA methylation biomarker candidates for early detection of colon cancer. Tumor Biology, 33(2), $363-372$. 
78. Zhang J, Hu S, Li Y. (2019). KRT18 is correlated with the malignant status and acts as an oncogene in colorectal cancer. Bioscience reports, 39(8).

79. Zhang, F., Lin, J. D., Zuo, X. Y., Zhuang, Y. X., Hong, C. Q., Zhang, G. J., ... Cui,Y. K. (2017). Elevated transcriptional levels of aldolase A (ALDOA) associates with cell cycle-related genes in patients with NSCLC and several solid tumors. BioData mining, 10(1), 1-20.

80. Zhu C, He L, Zhou X, Nie X, Gu Y. Sulfatase 2 promotes breast cancer progression through regulating some tumor-related factors. Oncol Rep. 2016;35(3):1318-28.

81. Zoppino FC, Guerrero-Gimenez ME, Castro GN, Ciocca DR. Comprehensive transcriptomic analysis of heat shock proteins in the molecular subtypes of human breast cancer. BMC Cancer. 2018;18(1):117.

\section{Figures}




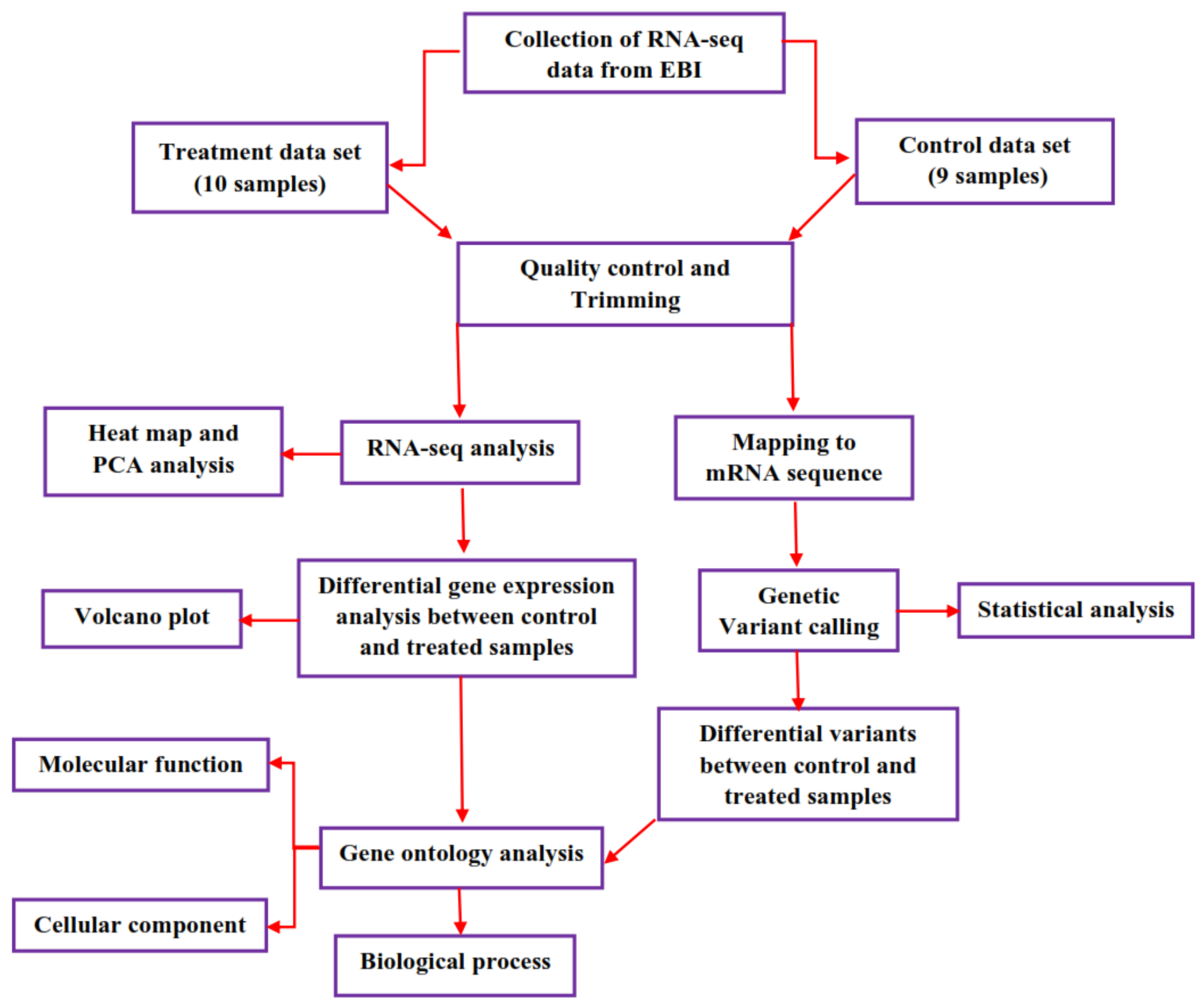

Figure 1

The summary of genetic variants detection and RNA-seq analysis of breast cancer cell line under Tamoxifen therapy. 


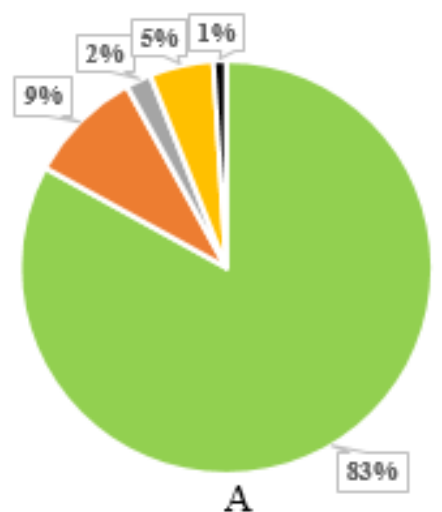

A

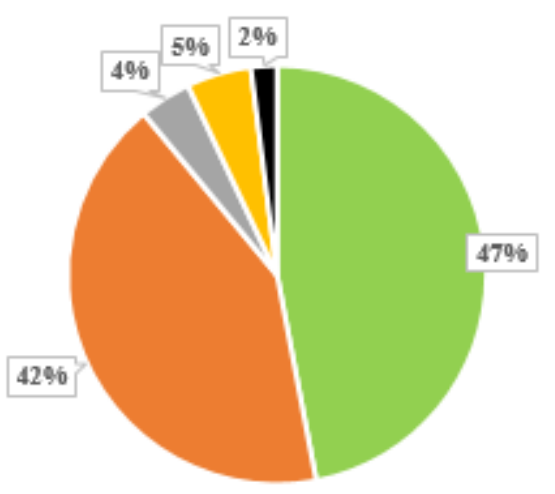

$\mathrm{C}$

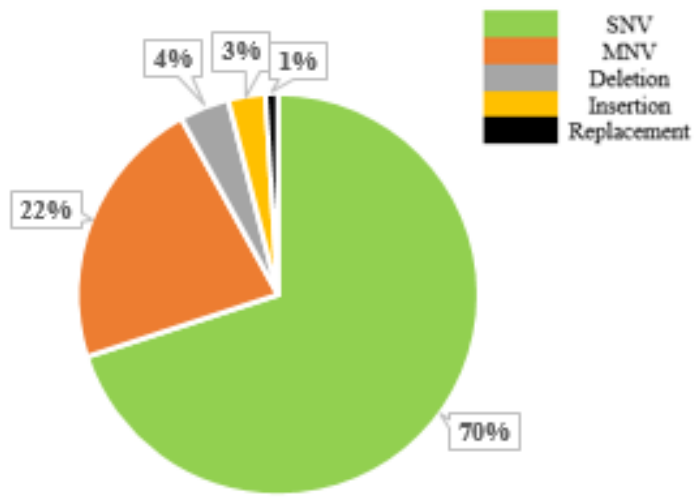

B

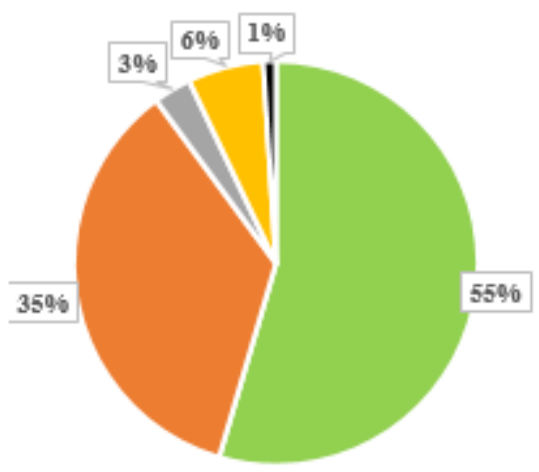

$\mathrm{D}$

Figure 2

Frequencies of reported genetic variants in the control and treated samples. Parts A and B illustrate the frequencies of detected genetic variants within control and treated samples. A total number of 2,853,482, and 2,988,729 genetic variants were reported for control and treated samples. 


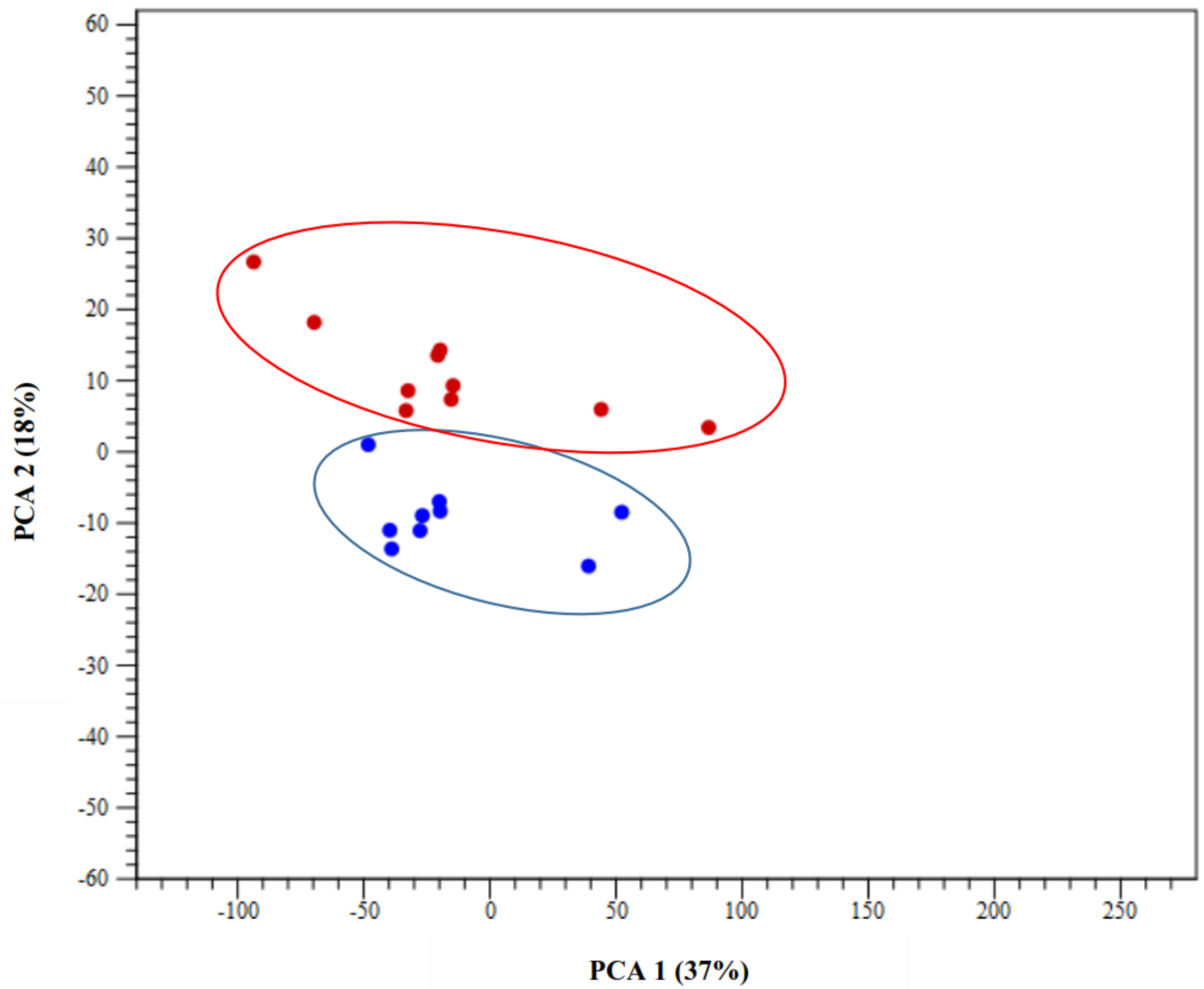

Figure 3

The classification of control and treated samples using PCA based on RNA-seq analysis results. Blue and red points show the control and treated samples. Results indicated that hormone therapy may influence the gene expression profile among treated and control samples. 


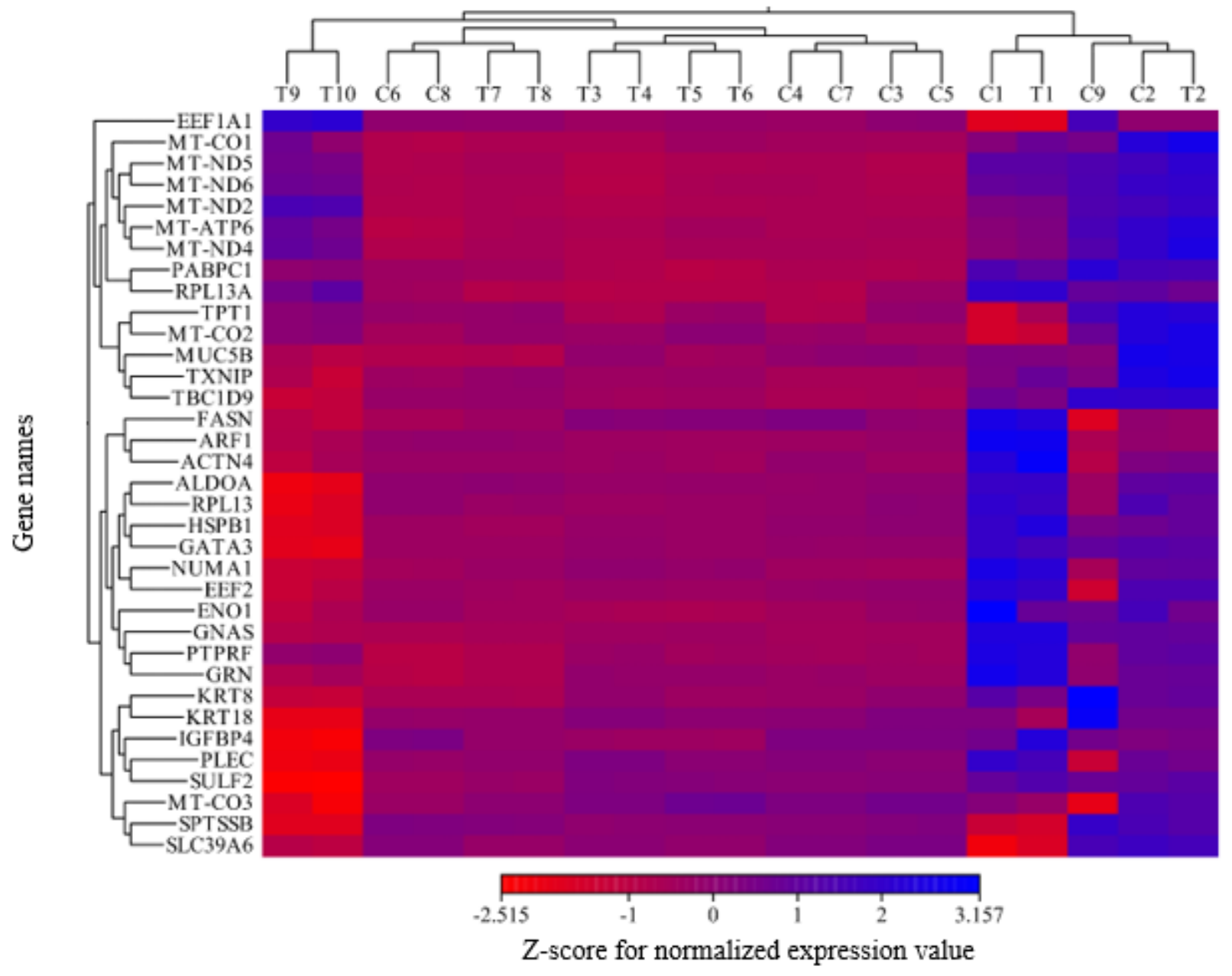

Figure 4

The heat map of RNA-seq analysis for control and treated samples 


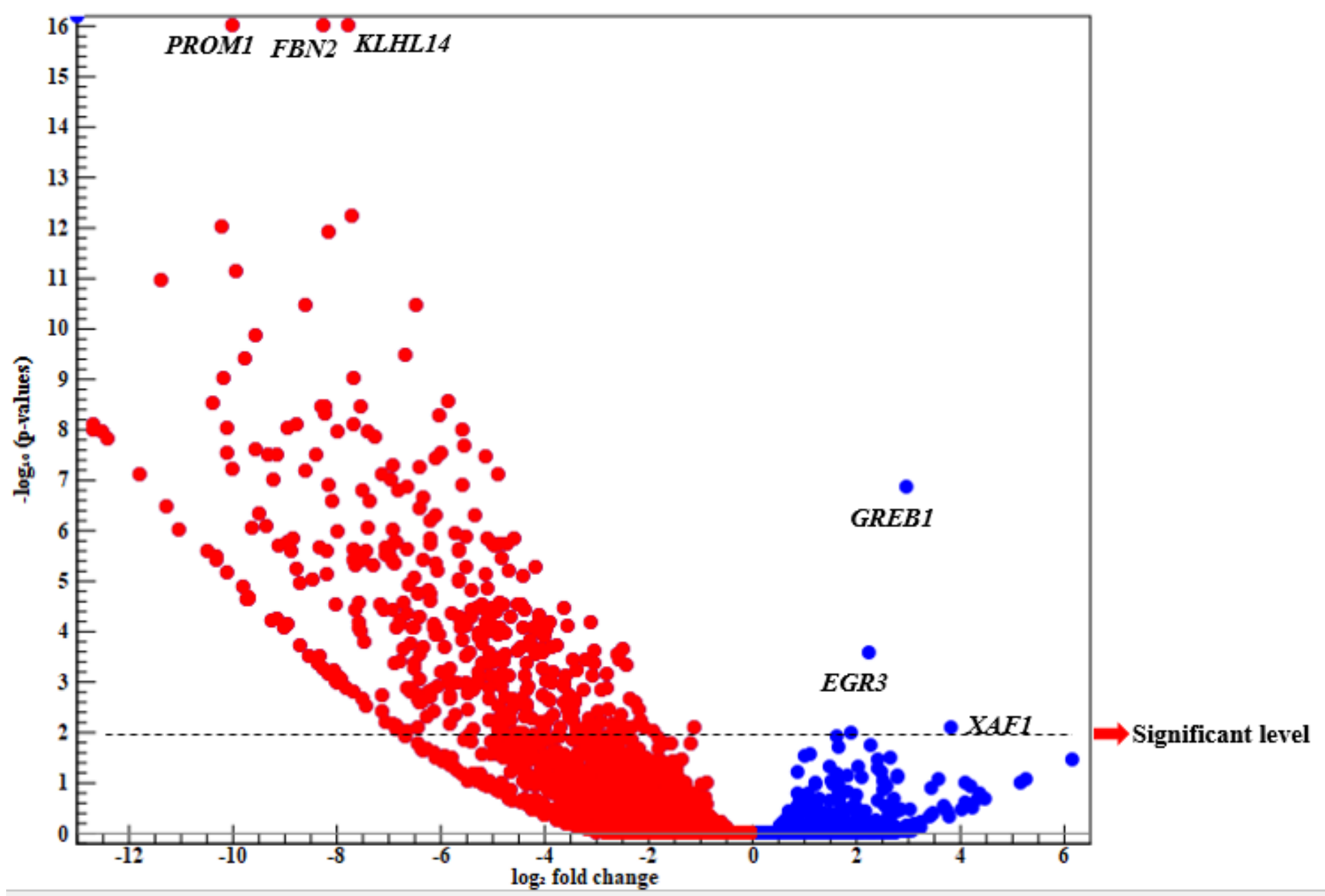

Figure 5

Results of Volcano plot that visualized the distribution of significant DGEs. Volcano plot shows the statistical significance (-log10 (P-value)) versus log2 (fold change) value. Also, the up- and downregulated genes were respectively shown in blue and red, while the most statistically significant genes were towards the top of dash line. 